\title{
Tropical origin, global diversification and dispersal in the pond damselflies (Coenagrionoidea) revealed by a new molecular phylogeny
}

\author{
B. Willink ${ }^{1,2 *}$, J. Ware ${ }^{3}$, E. I. Svensson ${ }^{4}$ \\ ${ }^{1}$ Department of Zoology, Stockholm University, Stockholm 106-91, Sweden \\ ${ }^{2}$ School of Biology, University of Costa Rica, San José 11501-2060, Costa Rica \\ *Corresponding author email: beatriz.willink@zoologi.su.se \\ $10{ }^{3}$ Division of Invertebrate Zoology, American Museum of Natural History, NY, NY, 10024, USA \\ ${ }^{4}$ Department of Biology, Evolutionary Ecology Unit, Ecology Building, Lund University, Lund \\ 223-62, Sweden
}

5

15 Keywords: biogeography, extinction, graphical models, latitudinal diversity gradient, paleogeography, speciation 


\begin{abstract}
Aim: The processes responsible for the formation of Earth's most conspicuous diversity pattern,

20 the latitudinal diversity gradient (LDG), remain unexplored for many clades in the Tree of Life. Here, we present a densely-sampled and dated molecular phylogeny for the most speciose clade of damselflies worldwide (Odonata: Coenagrionoidea), and investigate the role of time, macroevolutionary processes and dispersal dynamics in shaping the LDG in this ancient insect superfamily.
\end{abstract}

25 Location: global

Time period: $240-0$ mya

Major taxa studied: pond damselflies (Coenagrionidae) and featherlegs (Platycnemididae)

Methods: We used a process-based biogeographic model to jointly infer ancestral ranges and speciation times and to characterise dispersal dynamics between latitudinal regions. We then used

30 this phylogenetic inference to investigate temporal and latitudinal variation in diversification rates.

Results: Our results uncover a tropical origin of pond damselflies and featherlegs $\sim 105$ mya, with their common ancestor arising in either Northern South America or Western Africa. While diversification rates have declined since the origin of this clade, the tropics have acted as a net

35 source of lineages dispersing into temperate areas, where both speciation and extinction rates have been relatively higher.

Main conclusions: This study underscores the importance of biogeographic origin and time to diversify as important drivers of the LDG in pond damselflies. Diversification dynamics may have instead resulted in the formation of ephemeral species in temperate regions. Dispersal has 40 played a role reducing the steepness of the LDG, rather than amplifying it, which would have 
been expected under strong tropical niche conservatism. With ongoing climate change and increasing northward range expansions of many damselfly taxa, the LDG may continue to shallow. Our results support recent calls to unify biogeographic and macroevolutionary approaches to increase our understanding of how latitudinal diversity gradients are formed and 45 why they vary across time and among taxa. 


\section{INTRODUCTION}

A striking feature of species diversity is the non-uniformity of its global and regional distribution. Diversity gradients give us with a window into the processes that lead to the accumulation, loss

50 and turnover of evolutionary lineages. These problems already interested both Darwin (1859) and Wallace $(1876,1878)$, who were the first biologists to raise questions about the geographic distribution of extant taxa in an evolutionary framework. Darwin and Wallace were both fascinated by the high species diversity of tropical regions compared to temperate areas, and proposed possible explanations for this pattern, which later became known as the Latitudinal

55 Diversity Gradient (LDG) (Hillebrand, 2004).

Wallace (1878) suggested that climatic fluctuations, such as Pleistocene glaciations, were more pronounced in temperate regions, and this meant that there has been a smaller amount of time available for diversity to accumulate in these areas compared to the tropics. Both Darwin (1859) and Wallace (1878) saw the climatic stability of the tropics as a factor hindering extinction, and

60 believed that stronger biotic interactions in the tropics could accelerate speciation. These early bigeographic hypotheses were further developed by ecologists and evolutionary biologists throughout the twentieth century (Dobzhansky, 1950; Fischer, 1960; MacArthur, 1969). The stark contrast in species richness between tropical and temperate areas of the world has since been investigated in numerous comparative studies, and the evolutionary causes of the LDG remain a

65 highly active area of research (e.g. Hanly et al., 2017; Economo et al., 2018; Rabosky et al., 2018; Gaboriau et al., 2019; Saupe et al., 2019; Meseguer \& Condamine, 2020; Miller \& RománPalacios, 2021).

Current hypotheses to explain the causes of the LDG can be broadly categorized into those that emphasize ecological effects on diversification rates vs. those that emphasize time for speciation

70 in different regions and the contingencies of evolutionary history (Pianka, 1966; Mittelbach et al., 2007; Wiens, 2011). At one end of this dichotomy, the tropics are portrayed as ecology-fuelled 
species pumps, due to higher speciation rates (Wiens, 2007), lower extinction rates (Weir \& Schluter, 2007; Pyron, 2014) or both (Jablonski et al., 2006; Pyron \& Wiens, 2013; Rolland et al., 2014). The tropics have also been suggested to be the sources of most evolutionary novel lineages

75 due to their greater geographical area (Rosenzweig \& others, 1995; Belmaker \& Jetz, 2015), greater niche heterogeneity (Moritz et al., 2000; Salisbury et al., 2012), stronger biotic interactions (Dobzhansky, 1950; Schemske et al., 2009), or higher mean temperature (Wright et al., 2006; Brown, 2014). As Darwin and Wallace already anticipated, tropical diversity might also be buffered from the extinction that occurs in temperate regions because of greater climatic

80 instability (Dynesius \& Jansson, 2000; Jablonski et al., 2006; Hawkins et al., 2007). In contrast, studies at the other end of the dichotomy have proposed that the amount of time available for diversification might be the predominant cause of variation in regional species richness, whether aligned or contrary to the LDG (Stephens \& Wiens, 2003; Stevens, 2006; Economo et al., 2018; Miller \& Román-Palacios, 2021).

85 Understanding how ecological effects and historical contingencies shape regional diversification dynamics is therefore fundamental for a full understanding of the LDG, and it is crucial to critically evaluate the empirical evidence for these contrasting alternatives (Wiens, 2011). However, regional biotas are not only shaped by varying speciation and extinction rates but also by dispersal (Salisbury et al., 2012; Smith et al., 2012; Antonelli et al., 2015; Jablonski et al.,

90 2017). Dispersal is a fundamental process that determines whether existing lineages can successfully establish in an ecologically novel region (Wiens \& Graham, 2005). Moreover, diversification and dispersal may not act independently (Goldberg et al., 2011). For example, ecological limits to diversity, if present, could potentially reduce both speciation rates and the probability of successful establishment of new lineages that dispersed from other regions (Etienne 95 et al., 2019). Similarly, ecological specialization and niche partitioning may result in fast speciation locally, but trade-off with the evolution of dispersal ability (Jocque et al., 2010; 
Salisbury et al., 2012; Polato et al., 2018). Despite a potential key role of dispersal in molding the LDG, a prevailing focus on diversification dynamics may have curbed our understanding of the relative roles of each of these processes shaping regional biotas (Roy \& Goldberg, 2007).

100 To date, only a few studies have examined the combined effects of speciation, extinction and dispersal in shaping diversity gradients (Antonelli et al., 2015; Rolland et al., 2015; Spano et al., 2016; Jablonski et al., 2017; Owens et al., 2017). The majority of these studies target clades with a relatively rich fossil record, which also allows for process-based methods for inferring timecalibrated phylogenies (Ronquist et al., 2012; Heath et al., 2014). A first challenge to disentangle

105 how the birth, death and movement of lineages shape regional biotas is to generate data on the temporal and spatial patterns of diversification and dispersal for a greater variety of taxa. However, most organisms do not fossilize well (Kidwell \& Holland, 2002), and therefore other process-based methods are necessary to calibrate molecular clocks and infer ancestral geographic ranges (e.g. Tiley et al., 2020).

110 Biogeographic dating approaches have been long used as an alternative to fossil dating, but until recently, most of these methods relied on node calibrations (Kodandaramaiah, 2011; De Baets et $a l ., 2016)$ and have consequently failed to consider the joint probability of alternative diversification and dispersal scenarios (Ho et al., 2015). Landis (2017) introduced a datadependent generative model, in which the observed geographic ranges at the terminal nodes of

115 the tree induce a joint posterior distribution of speciation times and ancestral geographic states. Here, we capitalised on this and other statistical and methodological developments to investigate the phylogenetic and biogeographic history of a globally-distributed group of insects, the damselfly superfamily Coenagrionoidea (Carle et al., 2008; Bybee et al., 2021).

Our target clade includes two families: the pond damselflies (family Coenagrionidae) and their 120 close relatives the featherlegs (family Platycnemididae). Together, these two families constitute the most speciose clade of damselflies (Odonata: Zygoptera) worldwide (Dijkstra et al., 2014; 
Bybee et al., 2021). Different clades within Coenagrionidae exemplify both adaptive (Jordan et al., 2003; Toussaint et al., 2019) and non-adaptive evolutionary radiations (McPeek \& Brown, 2000; Siepielski et al., 2010). However, few molecular studies have examined the phylogenetic 125 relationships within Coenagrionoidea (Carle et al., 2008; Dijkstra et al., 2014; Waller \& Svensson, 2017; Toussaint et al., 2019; Kohli et al., 2020; Bybee et al., 2021), and a single dated and species-level phylogeny currently includes this clade (Waller \& Svensson, 2017). This species-level phylogeny nonetheless used phylogenetically-unsupported taxonomy as backbone. There is clearly a need for an updated phylogeny with denser taxon sampling, and for modern

130 phylogenetic comparative analyses to uncover large-scale diversity patterns and their drivers in this ancient group of insects.

Here, we present the most extensively sampled phylogeny of pond damselflies and their relatives to date. We then use this new phylogeny to address how diversification dynamics and dispersal have shaped regional species richness and the LDG. We include over 35\% of the approximately

1351,805 species, and thereby substantially increase the phylogenetic coverage of sampled taxa compared to previous studies (Dijkstra et al., 2014; Waller \& Svensson, 2017). Recent phylogenomic studies have produced a robust and dated backbone for the order Odonata, which we used to inform the origin time of the most recent common ancestor of pond damselflies and featherlegs (Kohli et al., 2020; Suvorov et al., 2021). We combine this root age prior with an 140 empirical paleogeographic model (Landis, 2017), genetic data and distribution range data of extant taxa, to simultaneously infer the divergence times and geographic distribution of ancestral lineages. We also use this time-calibrated phylogeny to quantify temporal and geographic patterns of diversification in pond damselflies and featherlegs, and to investigate the role of dispersal in shaping regional diversity. Our results provide a comprehensive overview of the

145 macroevolutionary history of this insect group and shed new light on the question of how speciation, extinction and dispersal shape global diversity patterns. 


\section{METHODS}

Here, we summarize the main features of the phylogenetic analyses performed in this study. For a detailed description of data collection, sequence alignment and the statistical approach used for

150 biogeographic dating, diversification and dispersal analyses, see Appendix S1 in the Supporting Material. All novel sequence data used in this study will be uploaded to NCBI Genbank. The sequence alignment, distribution data and code necessary to reproduce our results will be uploaded on Dryad (https://datadryad.org/stash) and are currently available on Github (https://github.com/bwillink/Damsel_Phylo). Phylogenetic analyses were partly conducted on the

155 computer cluster at the LUNARC Center for Scientific and Technical Computing, Lund University, Sweden.

\section{Sequence data and tree topology inference}

We sampled a total of 669 taxa in the Coenagrionoidea superfamily, 556 of which are currently classified as Coenagrionidae and 113 as Platycnemididae (Fig. 1, Table S1, S2). In a recent

160 phylogenomic study, the small family Isostictidae was recovered as sister to the clade including both Coeangrionidae and Platycnemididae (Bybee et al., 2021). As we did not sample Isostictidae, we hereafter use the superfamily name Coenagrionoidea to refer to Coenagrionidae (pond damselflies) and Platycnemididae (featherlegs) only. Samples were collected in the field, or obtained from specimens in museum and private collections, and publicly available data on NCBI

165 (https://www.ncbi.nlm.nih.gov/genbank/). For each species, we obtained sequence data for up to five loci (cytochrome oxidase subunit I, 16S ribosomal DNA, histone 3, phenyl-methyltransferase and 28S ribosomal DNA). Our molecular data consists of 1695 new sequences, 564 previously published sequences, and 105 unpublished sequences from the Naturalis Biodiversity Center, The Netherlands. We conducted all phylogenetic analyses using probabilistic graphical models and

170 Bayesian inference for parameter estimation, using RevBayes v. 1.0.7 and v. 1.0.12 (Höhna et al., 2014, 2016). 
Our first analysis aimed to infer the topology of the Coenagrionoidea phylogeny. We used a rooted uniform tree prior and a partitioned data scheme accounting for substitution rate variation among loci and among codon positions of coding sequences (Table S3). We specified a General

175 Time-Reversible (GTR) model of molecular evolution for each partition, and accounted for rate heterogeneity among sites by assuming gamma-distributed rate heterogeneity. Finally, we used a topological constraint to enforce the monophyly of each of the two families within Coenagrionoidea (Coenagrionidae and Platycnemididae), as supported by recent large-scale studies (Kohli et al., 2020; Bybee et al., 2021; Suvorov et al., 2021). The maximum a posteriori

180 probability (MAP) tree was used to summarize phylogenetic inference.

\section{Biogeographic dating with empirical paleogeography}

Next, we simultaneously inferred speciation times and ancestral distributions across the Coenagrionoidea tree using the empirical paleogegraphic model and statistical approach developed by Landis (2017). Instead of relying on internal node calibrations, this approach jointly

185 models ancestral dispersal and speciation events as conditional on historical shifts in oceanic barriers and the distribution ranges of extant taxa. To use biogeography in node-age estimation, we recorded species distributions from the literature, museum collections, IUCN Red List assessments and reputable web sources for all extant taxa included in this study (Table S4). Due to the low spatial resolution and coarse-grained nature of available data, species distributions

190 were registered as presence or absence from administrative geographical regions (countries and states/provinces/territories for countries spanning multiple biogeographic areas; see below).

In the model developed by Landis (2017), dispersal can occur by three modes (short- mediumand long-distance), which are differentially limited by oceanic barriers. The empirical paleogeographic model captures historical changes in these water barriers due to continental drift

195 (Landis, 2017). Thus, paleogeography determines the probability of transitions between biogeographic states, for each dispersal mode and for each discrete time interval (epoch) since the 
maximum plausible root age of the tree. The transition probability over the duration of each epoch (in millions of years) depends on this epoch-specific transition matrix and on a biogeographic clock, which is in turn linked to the mean of the lognormal distribution of 200 uncorrelated molecular clocks (Landis, 2017). Therefore, the time-heterogeneous process describing the probability of dispersal events can inform branch length estimation in absolute time. For example, ancestral dispersal leading to a disjunct distribution in the present is inferred to occur with higher probability during time intervals (epochs) in which the currently disjunct land masses were adjacent, and hence connected by all three dispersal modes, than when they

205 were separated by small or large water barriers, which would have then required medium- and long-distance dispersal respectively.

Damselflies are aquatic insects with a terrestrial adult phase. They require fresh water habitats to breed and for larvae to develop (Corbet, 1999). As damselflies cannot survive in or on salt water, it is highly likely that their dispersal has been historically constrained by oceanic barriers. Yet,

210 Coenagrionoidea has a cosmopolitan distribution at present, ranging across all continents except for Antarctica and Greenland (Table S4, Fig. 2). Unlike the larger dragonflies (suborder Anisoptera), in which long-distance and sometimes trans-oceanic migration has been described (Wikelski et al., 2006; Anderson, 2009; Troast et al., 2016), the majority of damselflies are small, weak fliers and tend to be more sedentary. For these biological reasons, we considered that a

215 global biogeographic model of changes in dispersal routes due to continental drift would be a suitable approach to explore historical biogeography in these damselflies.

The empirical paleogeographic model in Landis (2017) consists of 25 biogeographic areas (Fig. 2, Table S5) and 21 epochs between 240 mya and the present (see Table S2 and Fig. S8 in Landis, 2017). We combined this model with a root age prior based on recent large-scale phylogenomic 220 studies of major families in the whole order Odonata (Kohli et al., 2020; Suvorov et al., 2021). These studies date the origin of Coenagrionoidea to $\sim 109$ and $\sim 116$ mya respectively. We placed 
a normal root age prior with a mean of 120 and standard deviation of 20 to reflect this prior knowledge on the origin time of Coenagrionoidea. The normal distribution was truncated between 240 mya, the approximate age of the most recent common ancestor (MRCA) of all

225 Odonata (Misof et al., 2014; Suvorov et al., 2021) and 40 mya, the minimum age according to the study with the youngest age estimate for Coenagrionoidea (Waller \& Svensson, 2017). This choice of prior density follows a strong belief that posterior origin times for Coenagrionoidea in previous phylogenomic studies (Suvorov et al., 2021) are unbiased and adequately capture nodeage uncertainty. Truncation at 40 and 240 mya in turn shows a strong a priori belief that the

230 MRCA of this superfamily is neither older than the inferred origin of the order nor is it younger than the minimum age in the study with the youngest age estimate for Coenagrionoidea.

To assess the impact of our strongly informed root age prior and the empirical paelogeographic model, we conducted two additional analyses to contrast our results. First, we ran an identical model but with a weakly informed root age prior, in which the MRCA of Coenagrionoidea

235 occurred with equal probability between 240 and 40 mya. Second, we conducted an analysis with a uniform prior on the root age, in this case bounded between 240 and 0 mya, and ignoring the empirical paleogeographic data. This latter analysis hence excluded all empirical data (except the inferred origin time of Odonata) that could inform absolute divergence times and timeheterogeneous dispersal rates between biogeographic areas, and was used to rule out the

240 possibility that divergence times were influenced by artefacts arising from model construction.

For a comparison of this paleogeographic dating approach to a dating analysis informed by fossil constraints and a pure-birth model see Appendix S1.

\section{Diversification through time and space}

We quantified the temporal and geographic dynamics of diversification in Coenagrionoidea using

245 the MAP tree from the dating analyses above. We used an episodic birth-death (EBD) model (Stadler, 2011; Höhna, 2015) to test for time-dependent diversification rate shifts since the 
MRCA of Coeangrionoidea. EBD analyses assume that diversification rates change through time in a piece-wise constant fashion, following a process of Brownian motion. Thus for each epoch, rates are centred around the estimate in the previous epoch going backwards in time (Höhna,

250 2015; Magee et al., 2020). We used an EBD model with 20 equal-length time intervals since the origin of Coenagrionoidea (see Appendix S1), and accounted for the phylogenetic distribution of missing taxa by specifying the sampling fraction in each of the main clades identified in the topology inference above (Höhna, 2014) (Fig. 1).

We used a Hidden State-Dependent Speciation and Extinction (HiSSE) model to estimate the

255 diversification rates in two latitudinal regions (tropical and temperate) while accommodating background diversification-rate heterogeneity across different branches of the tree (Beaulieu \& O’Meara, 2016). Heterogeneity in background diversification was taken into account by including a hidden trait with two states, which differed in their effects on diversification. Transitions between latitudinal and hidden states were modelled as anagenetic changes

260 (i.e. occurring along branches). For this analysis, latitudinal regions were assigned to each taxa based on present-day geography, and taxa with distribution ranges spanning across latitudinal regions were coded as missing data. Diversification rates in this model take incomplete taxon sampling into account, by specifying a sampling fraction at the superfamily level.

\section{Effect of dispersal on regional diversity}

265 We investigated latitudinal patterns of dispersal using two complementary approaches. First, we used 1000 trees that were randomly sampled from the joint inference of biogeographic histories and node ages in the biogeographic dating model. Dispersal estimates below incorporate branch length uncertainty, but these estimates only represent dispersal events in lineages that have survived to the present and were sampled. Anagenetic changes in biogeographic states were

270 counted as trans-latitudinal dispersal when a lineage dispersed between biogeographic areas (e.g. from South America (N) and to North America (E)), during a period of time in which the 
ancestral and new biogeographic areas were in different latitudinal regions. We assigned latitudinal regions to each of the biogeographic areas at roughly $5 \mathrm{My}$ intervals since the oldest plausible age of Coenagrionoidea (240 mya, see Biogeographic dating with empirical

275 paleogeography above). To quantify the relative contribution of dispersal to tropical and temperate phylogenetic diversity, we computed the rate at which lineages depart from and become established in each latitudinal region, relative to the total phylogenetic diversity apportioned by each region (See Appendix S1 and Fig. S2). These estimates of departure and establishment rates for each latitudinal region thus also take into account latitudinal shifts of

280 biogeographic areas due to continental drift.

In our second approach, we used character histories sampled through stochastic character mapping from the HiSSE analysis described above (Freyman \& Höhna, 2019). Here, latitudinal states were assigned to terminal nodes based on present-day geography and the analysis was run on a single MAP tree. We therefore did not account here for branch-length uncertainty or

285 continental drift. However, the advantage of this approach is that the joint inference of character histories was conditional on the state-dependent diversification model, which can help untangle the contributions of dispersal and diversification to regional diversity (Maddison, 2006). In this and previous analyses, we report the posterior mean (PM) and 95\% highest posterior density (HPD) intervals for parameter estimates. Phylogenetic inferences and parameter estimates were

290 summarized using R (R Core Team, 2021). Plots we produced with the R packages ggplot2 (Wickham, 2016) and ggtree (Yu et al., 2017).

\section{RESULTS}

\section{Dated phylogeny and ancestral biogeography}

Our biogeographic dating analysis using a strongly informed root calibration returned a mean age 295 estimate for the MRCA of Coenagrionidae and Platycnemididae of 105 my (95\% HPD interval = 
64 - 145 my; Fig. 3). In contrast, applying a broad uniform prior on the root age resulted in a much younger estimate of 67 my (95\% HPD interval = $40-118$ my; Fig. 3). An analysis excluding empirical paleogeographic data produced, as expected, a flat posterior root age distribution between 240 and 0 mya (Fig. 3). Finally, an analysis excluding paleogeographic data

300 and relying on fossil constraints for node-dating returned an even younger root age estimate of 51 my $(95 \%$ HPD interval $=40-74$ my). Relatively shallow nodes (i.e. at the level of genera) in biogeographic dating analyses, and particularly in the analysis with a strongly informed root age prior, had older age estimates than in previous studies of comparable clades, and also older age estimates than in our fossil-based approach (Table S6). Despite large dating differences between

305 the two biogeographic analyses in this study, biogeographic trends were qualitatively similar between strongly informed and weakly informed models (see Appendix S2; Fig. S4-S9). Here, we focus on results under the strongly informed prior, and present the full results under the weakly informed prior in the Supporting Material (Appendix S2).

Extant pond damselflies and featherlegs are globally distributed, with a predominant presence in

310 the tropics (Fig. 2). Our ancestral biogeographic inference indicated that Coenagrionoidea most likely originated in either Northern South America or Western Africa (Fig. 2; S3), as these two ancestral ranges combined accounted for $88 \%$ of the posterior samples of the root state. The two extant lineages descending from this common ancestor had contrasting biogeographic histories. The featherlegs (family Platycnemididae) originated in Western Africa (PS = 0.959, Fig. 2; S3)

315 and likely dispersed throughout the Old World after multiple departures from Africa (Fig. 2; S4S5). The pond damselflies (family Coenagrionidae) are in turn composed of two clades with distinct dispersal dynamics. The 'ridge-face' clade of pond damselflies (sensu Dijkstra et al., 2014), including also the helicopter damselflies, the neotropical threadtails, and the dancers (genus Argia), originated with high probability in Northern South America (PS = 0.999; Fig. 2;

320 S3). This clade has remained largely neotropical, with a few successful dispersal events to the 
Nearctic (in Argia and Nehalennia), tropical Africa and Asia (in Ceriagrion) and presumably also across the Pacific (Melanesobasis, Teinobasis, Amphicnemis and allied genera) (Fig. 2; S6-S7). Finally, the "core" pond damselflies (sensu Dijkstra et al., 2014) have a much more dynamic dispersal history, particularly in the genus Ischnura (Fig. 2; S8-S9), and currently occupy all

325 available biogeographic areas and many oceanic islands not considered in this analysis (e.g. Megalagrion in Hawaii; Fig. S8-S9). While the origin of 'core' pond damselflies is also tropical, the geographic range of their MRCA remains elusive (Fig. 2; S3).

\section{Temporal dynamics of diversification}

Our EBD analysis showed a decline in the rate of speciation since the origin of Coenagrionoidea,

330 particularly between 85 - 55 mya (Fig. 4a). This analysis also detected a recent but modest increase in extinction (Fig. 4b). The combined effects of speciation and extinction dynamics resulted in a relatively constant net diversification rate in the early history of Coenagrionoidea, followed by a period of declining diversification ( $~ 85-55$ mya) and another period of constant to slowly declining diversification ( $\sim 55$ mya to the present) (Fig. 4c). As a result of increasing

335 extinction over the last $5 \mathrm{my}$, the 95\% HPD interval of diversification over this period includes the possibility of net diversity loss near the present (Fig. 4c).

EBD dynamics modeled on the dated phylogeny under a weakly informed root-age prior are qualitatively similar to the patterns described above (Fig. S10). However, these results contrast our previous analysis in two ways. First, there is a sharper decline in the rate of speciation after

340 the early period of constant birth (Fig. 4a, vs. S10a). Second, the increase in extinction over the last $5 \mathrm{my}$ is negligible and therefore, the lower bound of 95\% HPD interval for the rate of net diversification near the present remained positive.

\section{Latitudinal variation in diversification and dispersal}

As in the paleogeographic dating analysis, the HiSSE model inferred a tropical distribution with

345 high certainty for the MRCA of pond damselflies and featherlegs (Fig. S12). Following dispersal 
from the tropics, both speciation and extinction showed a trend toward acceleration in the temperate region (Table S7; Fig. 5a,b). Faster gain and loss of diversity through elevated speciation and extinction rates in the temperate region thus resulted in indistinguishable net diversification across latitudes (Fig. 4c).

350 We note that speciation rate estimates were more uncertain in the lineages with faster background diversification (hidden state 2) (Fig. 5a). This rapidly diversifying state was relatively rare across the Coenagrionoidea phylogeny. In fact, ancestral taxa with a high posterior frequency of this diversity-enhancing hidden-state were only found in three clades: the genus Enallagma (bluets), a Northamerican clade in the genus Ischnura (forktails), and a largely neotropical clade in the 355 genus Argia (dancers) (Fig. S14).

Results of the HiSSE analysis using the MAP tree under a weakly informed root-age prior were qualitatively similar (Table S7; Fig. S11). In this latter analysis more inclusive clades were assigned with high frequency to the diversity enhancing hidden state (Fig. S15). Therefore, latitude-dependent diversification rates were less uncertain in these rapidly diversifying clades 360 (Fig. S11).

Trans-latitudinal dispersal in Coenagrionoidea has been rare, and occurred at similar rates out of and into the tropics (Fig. S16). Ancestral state reconstruction under the paleogeographic dating model returned a posterior mode of 96 trans-latitudinal dispersal events departing from biogeographic areas in the tropics and a posterior mode of 20 dispersal events departing from

365 biogeographic areas in the temperate region (Fig. S17a). Stochastic character mapping in the HiSSE analysis, which takes incomplete taxon sampling and state-dependent diversification into account but ignores continental drift, resulted in a mode of 53 dispersal events from the tropics to the temperate region and 17 dispersal events from the temperate region to the tropics (Fig. S17b). 
Accounting for total phylogenetic diversity in each region revealed that this disparate lineage

370 exchange caused a net loss of diversity for the tropics, with relatively fewer incoming lineages than outgoing ones (Table S8; Fig. 6). In contrast, for temperate regions, high dispersal from the tropics resulted in a net gain of phylogenetic diversity (Table S8: Fig. 6). Contrasts between departure and establishment rates within regions also show that dispersal to the temperate region typically occur along shorter branches than dispersal back to the tropics (Table S8). This pattern

375 of relatively high departure from the tropics and relatively high establishment in the temperate region was found in both the paleogeographic dating analysis and the HiSSE analysis (Fig. 6). However, the rate of dispersal from the tropics to the temperate region, and therefore estimates of tropical departure and temperate establishment relative to regional phylogenetic diversity, were higher in the ancestral state reconstruction from the paleogeographic dating analysis (Table S8;

380 Fig. S17). Patterns of trans-latitudinal dispersal were nearly identical under the weakly informed root-age prior (Table S8; Fig. S18-S19).

\section{DISCUSSION}

In this study, we used a combination of biogeographic and multi-locus sequence data from extant taxa, an empirical paleogeographic model (Landis, 2017), and dating priors from recent

385 phylogenomic analyses (Kohli et al., 2020; Suvorov et al., 2021). Our goal was to understand the causes and consequences of diversification and dispersal dynamics in the most speciose superfamily of damselflies. While inferences about the age of Coenagrionoidea are notably sensitive to prior information (Fig. 3), our ancestral biogeographic reconstructions are robust to node age uncertainty (Fig. S3-S9). These analyses uncovered a tropical origin of

390 Coenagrionoidea, presumably in Northern South America or Western Africa, followed by dispersal to all continents, except for Antarctica and Greenland (Fig. 2). 
Despite their success in colonizing most of the world's land masses, diversification rates in Coenagrionoidea have declined since their evolutionary origin (Fig. 4). Diversification dynamics also vary between latitudinal regions, with temperate lineages undergoing faster speciation and

395 extinction, but with no detectable consequences for net diversification (Fig. 5). In contrast, dispersal, has resulted in a net gain of phylogenetic diversity in the temperate region and a net loss for the tropics (Fig. 6). Our results suggest an early start of tropical diversification as the main driver of the LDG in Coenagrionoidea. Diversity gains due to dispersal and accelerated speciation in the temperate region have counteracted the LDG, yet these effects may be at least

400 partially swamped by the relatively fast pace of damselfly extinctions outside the tropics.

When we combined empirical paleogeography with prior information on the root age of Coenagrionoidea, we obtained an estimated time for the MRCA of 105 mya (Fig. 3). This estimate is only slightly younger, yet more uncertain, than the age of Coenagrionoidea in the phylogenomic studies used for calibration (Kohli et al., 2020; Suvorov et al., 2021). Our

405 estimates of internal node ages under the strongly informed prior are also consistent with most fossil records, except for specimens attributed to Platycnemididae, which have been dated to $~ 99$ mya (Zheng et al., 2017), before the inferred origin of crown Platycnemidade in this analysis ( 80 mya; Table S6). Compared to shallow (genus-level) nodes dated in previous studies, inferred ages in this analysis are relatively older (Table S6). In contrast, the dating analysis without a

410 strongly informed root age prior (weakly informed), returned a younger origin time for Coenagrionoidea (Fig. 3), which was also younger than estimates in previous studies (Table S6). However, this latter analysis produced age estimates for shallow nodes that were usually closer to estimates in previous studies (see for example Ischnura, Enallagma, Nesobasis, Nehalennia and Platycnemis in Table S6).

415 These results underscore the challenges in dating phylogenies of groups of organisms with a scant fossil record, and the limitations of simple models of dispersal and paleogeography. The 
statistical approach developed by Landis (2017) is appealing for its ability to jointly sample dispersal histories and diversification events. However, the computational challenges to the likelihood calculation over a large space of states currently prohibits incorporating critical

420 complexity into the paleogeographic model (Ree \& Sanmartin, 2009). A terrestrial graph at a global scale seems suitable for widely distributed damselflies, which require fresh water habitats to breed (Corbet, 1999). Nonetheless, many genera of pond damselflies are endemic to specific archipelagos, while some taxa are widely distributed across continents (Fig. 2; Table S4). In the present analysis, island endemics are subsumed into larger biogeographic areas or coded as

425 missing data (see Appendix S1), and distribution ranges spanning two or more areas are treated as character-state uncertainty in extant taxa. A model that incorporates branch heterogeneity in dispersal rates and captures the more fine grained paleogeographic events that shaped the distribution of island endemics would likely improve bigeographic dating in this and other diverse groups of insects that vary in their ease of dispersal (e.g. Jones et al., 2016) and tend to

430 leave a relatively sparse fossil record (Wills, 2001). Yet, such extensions under a fully Bayesian approach are currently constrained by computational limitations.

Despite these challenges to node dating, both analyses under alternative root age priors indicate that the MRCA of pond damselflies and featherlegs originated in either Northern South America or Western Africa (Fig. 2; S3). These areas were separated by narrower water barriers at the

435 presumed origin of Coenagrionoidea (particularly under the strongly informed root age prior) and have preserved tropical rainforests throughout the Cenozoic, notwithstanding climatic change (Morley, 2007; Couvreur et al., 2011). The difficulty in distinguishing between these two biogeographical origins reflects the contrasting biogeographic histories of the main clades in Coenagrionoidea. The featherlegs have a historically Paleotropical distribution with a few

440 dispersal events to the temperate region in Europe and Asia (Fig. 2; S4-S5). The 'ridge-face' clade of pond damselflies had a Neotropical origin with limited dispersal across continents (Fig. 
2; S6-S7). Finally, the 'core' clade of pond damselflies includes the most dispersive lineages, such as the ancestors of almost all extant taxa currently present in Oceanic islands (Table S4), and most temperate lineages (Fig. 2; S8-S9). As is the case in general for rapidly evolving traits

445 (Schluter et al., 1997; Losos, 2011), rapid range shifts in the 'core' pond damselflies complicate inferences about ancestral ranges in this clade.

The early evolution of Coenagrionoidea was characterised by fast diversification, followed by a decline in the rate of accumulation of new species (Fig. 4). This is a common feature of dated phylogenies (Morlon et al., 2010), which has been subject to considerable controversy and which

450 can be attributed to several possible causes including statistical artefacts (reviewed in Moen \& Morlon, 2014). One possibility is that regional diversification slows down over time because niche space is reduced as species accumulate, eventually reaching some ecological limit (Rabosky, 2009; Etienne et al., 2011; Etienne \& Haegeman, 2012). In this scenario, speciation decreases from the origin of a clade until the region reaches equilibrium diversity, where 455 speciation and extinction cancel each other out, as in the classical theory of island biogeography (Wilson \& MacArthur, 1967). While plausible if contemporaneous taxa co-occur and compete for finite resources (Herrera-Alsina et al., 2018), this explanation for a decline in diversification with time seems less likely for non-ecological and non-adaptive radiations (Rundell \& Price, 2009; Czekanski-Moir \& Rundell, 2019). Some relatively young radiations in pond damselflies and 460 other odonates have resulted from non-ecological speciation mechanisms, such as sexual selection or sexual conflict, and many closely related taxa are therefore only weakly ecologically differentiated from each other (McPeek \& Brown, 2000; Siepielski et al., 2010; Svensson, 2012; Svensson et al., 2018). These features of damselfly communities suggest that niche partitioning does not strongly constrain speciation, although such weak niche differentiation might of course

465 impact the longevity of newly formed lineages, which can be subject to ecological drift and stochastic extinction [Siepielski et al. (2010); Svensson et al. (2018); see further below]. 
Alternatively, a decreasing rate of speciation over time may be caused by dynamic geographic conditions that influence the likelihood of speciation. Vicariance events which promote allopatric speciation are more likely to impact species with broad distributions, but vicariance also has the

470 effect of reducing the geographic range of descendant species (Pigot et al., 2010). For example, the formation of a mountain range could separate populations of a widely distributed species, prompting allopatric speciation. If subsequent range expansion is rare, future vicariance events are less likely to impact the range of all descendant taxa (and therefore maintain the speciation rate), simply because their distribution ranges are now reduced in extension (Pigot et al., 2010;

475 Price, 2010). A prediction of this geographic hypothesis is that the average size of species' ranges will decrease as the amount of time a clade has spent in a specific region increases. Comparative studies of range sizes and speciation rates at a broader latitudinal scale (e.g. Tanentzap et al., 2020) are necessary to asses empirical support for the role of geography in the temporal dynamics of diversification.

480 Finally, an apparent slowdown in diversification may arise from statistical artefacts or sampling biases. For example, underparametrized models of molecular evolution can lead to underestimation of branch lengths, particularly in older branches of the tree (Revell et al., 2005). As diversification rate estimation ultimately relies on the distribution of branch lengths across the tree, this type of model misspecification can result in an artificial slowdown of diversification

485 over time. An artificial slowdown can also be a product of incomplete lineage sampling, especially when taxon sampling is non-random (Cusimano \& Renner, 2010; Brock et al., 2011). However, in this study we have used methods that explicitly incorporate sampling fractions of specific clades as a measure to counter this bias (Höhna, 2015). Nonetheless, even when models are correctly specified and sampling of extant taxa is accounted for, the "push of the past" can

490 produce an apparent slowdown of diversification over time (Budd \& Mann, 2018). This survivorship bias occurs because we can only sample extant descendants from lineages which had 
high enough speciation rates as to have survived to the present. Deep branches in the tree that diversified more slowly, and would have contributed to a more constant estimate of diversification rates over time, are more likely to have gone extinct over the 105 my of

495 Coenagrionoidea evolution, thereby leaving no descendants from which to infer their lower diversification rates. The "push of the past" remains a challenge to estimating temporal diversification dynamics when we lack information of whether and how many entire clades have gone extinct (Budd \& Mann, 2018).

The present distribution of pond damselflies, as many other clades, is characterised by higher

500 species richness near the equator compared to temperate areas (Fig. 2) (Hillebrand, 2004; Kinlock et al., 2018). Our results indicated that none of the hypotheses based on accelerated speciation or reduced extinction in the tropics (see Introduction) is a likely explanation for why most extant damselfly species occur at low latitudes (Fig. 5). While taking background diversification heterogeneity into account (Beaulieu \& O’Meara, 2016), we found no difference in net

505 diversification rates between the tropical and temperate regions of the globe (Fig. $5 \mathrm{c}$ ). Nonetheless, speciation and extinction dynamics do tend to differ across latitudes, with both rates being higher in the temperate region, and thus cancelling each other out. As a consequence, temperate lineages tend to be relatively short lived and replace one another at a faster rate than tropical lineages do, resulting in higher turnover rates at high latitudes. Several studies have

510 uncovered a similar pattern of increased lineage turnover in the temperate region or in harsher non-tropical environments (Weir \& Schluter, 2007; Botero et al., 2014; Pyron, 2014; Harvey et al., 2020). More generally, speciation rates might actually be higher in areas with lower diversity, challenging previous assumptions of a strong causal link between past diversification rates and current diversity (Schluter \& Pennell, 2017).

515 Faster lineage turnover at higher latitudes may come about in at least two ways. First, paleoclimatic fluctuations (e.g. DeConto et al., 2008) can cause the fragmentation of distribution 
ranges, a phenomenon that is particularly pronounced at higher latitudes (Jansson \& Dynesius, 2002). By repeatedly creating isolated refugia, climate fluctuations may have episodically fostered allopatric speciation (Weir \& Schluter, 2004; Milá et al., 2007; Sánchez-Ramírez et al.,

520 2015; Morales-Barbero et al., 2018). However, the same recurrent climatic events can also increase extinction rates, either because range fragmentation reduces population size, or because hybridization and competitive exclusion drive extinction upon secondary contact (Dynesius \& Jansson, 2000; Barnosky, 2005; Botero et al., 2014). Furthermore, climate fluctuations at higher latitudes might open up novel ecological opportunities that prompt speciation, by constantly

525 renewing the availability of unoccupied niches (Schluter, 2016). High environmental harshness in these novel environments at high latitudes might also result in the predominance of viability selection driven by abiotic environmental conditions, potentially increasing extinction risk and thereby accelerating lineage turnover (Haldane, 1937; Gomulkiewicz \& Holt, 1995; Cutter \& Gray, 2016).

530 Whether it is driven by ecological factors (Cutter \& Gray, 2016; Schluter, 2016), or nonecological mechanisms (McPeek \& Gavrilets, 2006; Svensson et al., 2006; Siepielski et al., 2018), ephemeral speciation in temperate regions does not seem to have a net impact on diversification, in contrast to expectations from simulation studies (Cutter \& Gray, 2016). Our results therefore highlight the role of the historical origin of Coenagrionoidea in the tropics as the

535 main cause of the present-day LDG. This historical early start of diversification in the tropics has maintained the LDG despite an overall decrease in speciation rate (Fig. 4), and a net gain of lineages through dispersal in the temperate region (Fig. 6). Our findings that dispersal occurs at similar rates in and out of the tropics (Fig. S17) and that the net result of dispersal dynamics is increased phylogenetic diversity in the temperate regions, suggest that dispersal out of the tropics

540 may have decreased the steepness of the LDG, particularly towards the present. These results also run counter to previous studies that have found stronger niche conservatism (i.e. the tendency to 
remain in ancestral environments) in tropical lineages (Smith et al., 2012; Pyron \& Wiens, 2013). Strong niche conservatism in the tropics is expected if adaptations to colder and potentially harsher temperate environments are difficult to evolve (Wiens \& Donoghue, 2004). However,

545 recent studies show that diversity gradients may be similarly steep, regardless of the climatic conditions at the ancestral range (Boucher-Lalonde et al., 2015), and suggest that tropical ectotherms may actually be better at invading temperate regions than vice-versa (Amarasekare \& Simon, 2020).

The LDG in Coenagrionoidea has likely changed in steepness and will most likely continue to

550 change in the future, as has been the case for other taxonomic groups (Mannion et al., 2014). Although trans-latitudinal dispersal rates can be relatively low compared to in situ diversification due to niche conservatism (compare Fig. 5 and Fig. S11 to Fig. S16), successful dispersal out of the tropics allowed colonization of temperate areas in multiple lineages of Coenagrionoidea, and had a net effect of increasing phylogenetic diversity at high latitudes. As a result of an early start

555 of diversification in the tropics, followed by similar net diversification rates across latitudinal regions, the Coenagrioniodea LDG is expected to persist, unless an external input of diversity to the temperate areas reverses this general pattern. With ongoing global climate change currently affecting latitudinal environmental gradients (Loarie et al., 2009), and potentially also influencing trans-latitudinal dispersal (Paulson, 2001), such as in recent northward range expansions in

560 Europe (Grewe et al., 2013; Lancaster et al., 2015), the role of dispersal shaping the future steepness of the LDG warrants further investigation.

\section{Conclusion}

The damselfly superfamily Coenagrionoidea originated in tropical areas, where most of its diversity is currently found (Fig. 2). An increasing number of studies have revealed the

565 importance of both ecology and historical biogeography in producing regional differences in diversity across distinct clades of plants and animals (e.g. Rolland et al., 2014; Antonelli et al., 
2015; Jablonski et al., 2017). Here, we have shown that in pond damselflies and their relatives, early tropical diversification followed by dispersal out of the tropics established the latitudinal diversity gradient observed today. Faster ecological speciation in temperate regions is unlikely to

570 compensate for this time lag in the future, as speciation might be more ephemeral at higher latitudes (Fig. 5). However, regional species richness depends not only on diversification dynamics but also on dispersal. Over the course of Coenagrionoidea evolution, dispersal out of the tropics has resulted in a net gain of diversity for the temperate areas (Fig. 6), contrary to the expectation that niche conservatism should be more pronounced in the tropics. In the long term,

575 such differential dispersal might contribute to leveling out the current latitudinal diversity gradient. Our results reveal a complex interplay between history, macroevolutionary processes and dispersal shaping global diversity patterns.

\section{Acknowledgements}

We are grateful to Hanna Bensch, Robin Pranter, Tammy Ho, Chiara de Pasqual and Yassin

580 Tschinda for their ceaseless efforts to sample specimens in field and obtain sequence data in the lab. This study would have been impossible without the generosity and time of all the avid odonatologists and museum curators who made hundreds of specimens available to us and helped us with taxonomic identifications. We are particularly grateful to Bill Mauffray and Paul Skelly at the Florida State Collection of Arthropods, Oliver Flint and Floyd Shockley at the Smithsonian

\section{Institute, Darren Ward at the New Zealand Arthropod Collection, Darío Lijtmaer at the}

Argentinian Museum of Natural Sciences, and KD Dijkstra at the Naturalis Biodiversity Center. Many others contributed with samples and/or taxonomic expertise (Table S2). Specimens were collected with permits from the Guyana Environmental Protection Agency (Reference No. 010715 BR001 and 012615 SP: 002), the Secretaría de Ambiente y Desarrollo Sustentable, 590 Argentina (Ref No. 11084/16) and from the Cameroon Ministry of Forestry and Wildlife (Ref. No. 0000034). We acknowledge the logistic support from the Iwokrama International Centre for 
Rain Forest Conservation and Development, Guyana, the Karanambu Trust, Guyana, the National

Park Administration, Argentina, and the Congo Basin Institute, Cameroon. Funding for this study was provided by research grants from The Swedish Research Council (VR: grant no. 2016-

595 03356), the Swedish Foundation for International Cooperation in Research and Higher Education, and Erik Philip Sörensens Stiftelse to E.I.S and from The Royal Physiographic Society of Lund, the Jörgen Lindströms Fund and "Lunds Djurskyddsfond" to B.W. We thank Stephen De Lisle and Miguel Gómez-Llano for helpful comments on the manuscript.

\section{Author contributions}

600 EIS, BW and JW conceived the study. EIS and BW collected the field samples. BW collected the museum samples, performed the molecular laboratory work and designed and conducted the phylogenetic analyses. BW wrote the manuscript with input from EIS and JW. 


\section{References}

605 Amarasekare, P. \& Simon, M.W. (2020) Latitudinal directionality in ectotherm invasion success. Proceedings of the Royal Society B, 287, 20191411.

Anderson, R.C. (2009) Do dragonflies migrate across the western Indian Ocean? Journal of Tropical Ecology, 25, 347-358.

Antonelli, A., Zizka, A., Silvestro, D., Scharn, R., Cascales-Miñana, B. \& Bacon, C.D. (2015) An engine for global plant diversity: Highest evolutionary turnover and emigration in the American tropics. Frontiers in Genetics, 6, 130.

Barnosky, A.D. (2005) Effects of Quaternary climatic change on speciation in mammals. Journal of Mammalian Evolution, 12, 247-264.

Beaulieu, J.M. \& O'Meara, B.C. (2016) Detecting hidden diversification shifts in models of trait-dependent speciation and extinction. Systematic biology, 65, 583-601.

Belmaker, J. \& Jetz, W. (2015) Relative roles of ecological and energetic constraints, diversification rates and region history on global species richness gradients. Ecology Letters, 18, 563-571.

Botero, C.A., Dor, R., McCain, C.M. \& Safran, R.J. (2014) Environmental harshness is positively correlated with intraspecific divergence in mammals and birds. Molecular Ecology, 23, 259-268.

Boucher-Lalonde, V., De Camargo, R.X., Fortin, J.-M., Khair, S., So, R.I., Vazquez Rivera, H., Watson, D., Zuloaga, J. \& Currie, D.J. (2015) The weakness of evidence supporting tropical niche conservatism as a main driver of current richness-temperature gradients. Global Ecology and Biogeography, 24, 795-803.

Brock, C.D., Harmon, L.J. \& Alfaro, M.E. (2011) Testing for temporal variation in diversification rates when sampling is incomplete and nonrandom. Systematic Biology, 60, 410-419.

Brown, J.H. (2014) Why are there so many species in the tropics? Journal of Biogeography, 41, 8-22.

Budd, G.E. \& Mann, R.P. (2018) History is written by the victors: The effect of the push of the past on the fossil record. Evolution, 72, 2276-2291.

Bybee, S.M., Kalkman, V.J., Erickson, R.J., Frandsen, P.B., Breinholt, J.W., Suvorov, A., Dijkstra, K.-D.B., Cordero-Rivera, A., Skevington, J.H., Abbott, J.C. \& others (2021) Phylogeny and classification of Odonata using targeted genomics. Molecular Phylogenetics and Evolution, 160, 107115.

Carle, F.L., Kjer, K. \& May, M. (2008) Evolution of Odonata, with special reference to Coenagrionoidea (Zygoptera). Arthropod Systematics \& Phylogeny, 66, 37-44.

Corbet, P.S. (1999) Dragonflies: Behavior and ecology of Odonata. 
640 Couvreur, T.L.P., Forest, F. \& Baker, W.J. (2011) Origin and global diversification patterns of tropical rain forests: Inferences from a complete genus-level phylogeny of palms. BMC Biology, 9, 44.

Cusimano, N. \& Renner, S.S. (2010) Slowdowns in diversification rates from real phylogenies may not be real. Systematic Biology, 59, 458-464.

645 Cutter, A.D. \& Gray, J.C. (2016) Ephemeral ecological speciation and the latitudinal biodiversity gradient. Evolution, 70, 2171-2185.

Czekanski-Moir, J.E. \& Rundell, R.J. (2019) The ecology of nonecological speciation and nonadaptive radiations. Trends in Ecology \& Evolution, 34, 400-415.

Darwin, C.R. (1859) The origin of species by means of natural selection, or the preservation of favoured races in the struggle for life.

De Baets, K., Antonelli, A. \& Donoghue, P.C. (2016) Tectonic blocks and molecular clocks. Philosophical Transactions of the Royal Society B: Biological Sciences, 371, 20160098.

DeConto, R.M., Pollard, D., Wilson, P.A., Pälike, H., Lear, C.H. \& Pagani, M. (2008) Thresholds for Cenozoic bipolar glaciation. Nature, 455, 652-657.

Dijkstra, K.D.B., Kalkman, V.J., Dow, R.A., Stokvis, F.R. \& Van Tol, J.A.N. (2014) Redefining the damselfly families: A comprehensive molecular phylogeny of Zygoptera (Odonata). Systematic Entomology, 39, 68-96.

Dobzhansky, T. (1950) Evolution in the tropics. American Scientist, 38, 209-221.

660 Dynesius, M. \& Jansson, R. (2000) Evolutionary consequences of changes in species' geographical distributions driven by Milankovitch climate oscillations. Proceedings of the National Academy of Sciences, 97, 9115-9120.

Economo, E.P., Narula, N., Friedman, N.R., Weiser, M.D. \& Guénard, B. (2018) Macroecology and macroevolution of the latitudinal diversity gradient in ants. Nature Communications, 9, 1778.

Etienne, R.S., Cabral, J.S., Hagen, O., Hartig, F., Hurlbert, A.H., Pellissier, L., Pontarp, M. \& Storch, D. (2019) A minimal model for the latitudinal diversity gradient suggests a dominant role for ecological limits. The American Naturalist, 194, E122-E133.

670 Etienne, R.S. \& Haegeman, B. (2012) A conceptual and statistical framework for adaptive radiations with a key role for diversity dependence. American Naturalist, 180, E75-E89.

Etienne, R.S., Haegeman, B., Stadler, T., Aze, T., Pearson, P.N., Purvis, A. \& Phillimore, A.B. (2011) Diversity-dependence brings molecular phylogenies closer to agreement with the fossil record. Proceedings of the Royal Society of London B: Biological Sciences, 279, 1300-1309. 
Fischer, A.G. (1960) Latitudinal variations in organic diversity. Evolution, 14, 64-81.

Freyman, W.A. \& Höhna, S. (2019) Stochastic character mapping of state-dependent diversification reveals the tempo of evolutionary decline in self-compatible onagraceae lineages. Systematic Biology, 68, 505-519.

Gaboriau, T., Albouy, C., Descombes, P., Mouillot, D., Pellissier, L. \& Leprieur, F. (2019) Ecological constraints coupled with deep-time habitat dynamics predict the latitudinal diversity gradient in reef fishes. Proceedings of the Royal Society $B$, 286, 20191506.

685 Goldberg, E.E., Lancaster, L.T. \& Ree, R.H. (2011) Phylogenetic inference of reciprocal effects between geographic range evolution and diversification. Systematic biology, 60, 451-465.

Gomulkiewicz, R. \& Holt, R.D. (1995) When does evolution by natural selection prevent extinction? Evolution, 49, 201-207.

690 Grewe, Y., Hof, C., Dehling, D.M., Brandl, R. \& Brändle, M. (2013) Recent range shifts of European dragonflies provide support for an inverse relationship between habitat predictability and dispersal. Global Ecology and Biogeography, 22, 403409.

Haldane, J.B.S. (1937) The effect of variation of fitness. The American Naturalist, 71, 337-349.

Hanly, P.J., Mittelbach, G.G. \& Schemske, D.W. (2017) Speciation and the latitudinal diversity gradient: Insights from the global distribution of endemic fish. The American Naturalist, 189, 604-615.

Harvey, M.G., Bravo, G.A., Claramunt, S., Cuervo, A.M., Derryberry, G.E., Battilana, J., Seeholzer, G.F., McKay, J.S., O’Meara, B.C., Faircloth, B.C. \& others (2020) The evolution of a tropical biodiversity hotspot. Science, 370, 1343-1348.

Hawkins, B.A., Diniz-Filho, J.A.F., Jaramillo, C.A. \& Soeller, S.A. (2007) Climate, niche conservatism, and the global bird diversity gradient. American Naturalist, 170, S16-S27.

705 Heath, T.A., Huelsenbeck, J.P. \& Stadler, T. (2014) The fossilized birth-death process for coherent calibration of divergence-time estimates. Proceedings of the National Academy of Sciences, 111, E2957-E2966.

Herrera-Alsina, L., Pigot, A.L., Hildenbrandt, H. \& Etienne, R.S. (2018) The influence of ecological and geographic limits on the evolution of species distributions and diversity. Evolution, 72, 1978-1991.

Hillebrand, H. (2004) On the generality of the latitudinal diversity gradient. American Naturalist, 163, 192-211. 
Ho, S.Y.W., Tong, K.J., Foster, C.S.P., Ritchie, A.M., Lo, N. \& Crisp, M.D. (2015) Biogeographic calibrations for the molecular clock. Biology Letters, 11, 20150194.

Höhna, S. (2014) Likelihood inference of non-constant diversification rates with incomplete taxon sampling. PLOS ONE, 9, e84184.

Höhna, S. (2015) The time-dependent reconstructed evolutionary process with a key-role for mass-extinction events. Journal of Theoretical Biology, 380, 321-331.

720 Höhna, S., Heath, T.A., Boussau, B., Landis, M.J., Ronquist, F. \& Huelsenbeck, J.P. (2014) Probabilistic graphical model representation in phylogenetics. Systematic Biology, 63, 753-771.

Höhna, S., Landis, M.J., Heath, T.A., Boussau, B., Lartillot, N., Moore, B.R., Huelsenbeck, J.P. \& Ronquist, F. (2016) RevBayes: Bayesian phylogenetic inference using graphical models and an interactive model-specification language. Systematic Biology, 65, 726-736.

Jablonski, D., Huang, S., Roy, K. \& Valentine, J.W. (2017) Shaping the latitudinal diversity gradient: New perspectives from a synthesis of paleobiology and biogeography. American Naturalist, 189, 1-12.

730 Jablonski, D., Roy, K. \& Valentine, J.W. (2006) Out of the tropics: Evolutionary dynamics of the latitudinal diversity gradient. Science, 314, 102-106.

Jansson, R. \& Dynesius, M. (2002) The fate of clades in a world of recurrent climatic change: Milankovitch oscillations and evolution. Annual Review of Ecology and Systematics, 33, 741-777.

735 Jocque, M., Field, R., Brendonck, L. \& De Meester, L. (2010) Climatic control of dispersal-ecological specialization trade-offs: A metacommunity process at the heart of the latitudinal diversity gradient? Global Ecology and Biogeography, 19, 244-252.

Jones, H.B.C., Lim, K.S., Bell, J.R., Hill, J.K. \& Chapman, J.W. (2016) Quantifying interspecific variation in dispersal ability of noctuid moths using an advanced tethered flight technique. Ecology and Evolution, 6, 181-190.

Jordan, S., Simon, C. \& Polhemus, D. (2003) Molecular systematics and adaptive radiation of Hawaii's endemic damselfly genus Megalagrion (Odonata: Coenagrionidae). Systematic Biology, 52, 89-109.

745 Kidwell, S.M. \& Holland, S.M. (2002) The quality of the fossil record: Implications for evolutionary analyses. Annual Review of Ecology and Systematics, 33, 561-588.

Kinlock, N.L., Prowant, L., Herstoff, E.M., Foley, C.M., Akin-Fajiye, M., Bender, N., Umarani, M., Ryu, H.Y., Şen, B. \& Gurevitch, J. (2018) Explaining global variation in the latitudinal diversity gradient: Meta-analysis confirms known patterns and uncovers new ones. Global Ecology and Biogeography, 27, 125-141. 
Kodandaramaiah, U. (2011) Tectonic calibrations in molecular dating. Current Zoology, 57, 116-124.

Kohli, M., Letsch, H., Greve, C., Bethoux, O., Deregnacourt, I., Liu, S., Zhou, X., Donath, A., Mayer, C., Podsiadlowski, L., Machida, R., Niehuis, O., Rust, W.T.Y., Jes, Xin, Misof, B. \& Ware, J. (2020) How old are dragonflies and damselflies? Odonata (Insecta) transcriptomics resolve familial relationships. bioRxiv.

Lancaster, L.T., Dudaniec, R.Y., Hansson, B. \& Svensson, E.I. (2015) Latitudinal shift in thermal niche breadth results from thermal release during a climate-mediated range expansion. Journal of Biogeography, 42, 1953-1963.

Landis, M.J. (2017) Biogeographic dating of speciation times using paleogeographically informed processes. Systematic Biology, 66, 128-144.

Loarie, S.R., Duffy, P.B., Hamilton, H., Asner, G.P., Field, C.B. \& Ackerly, D.D. (2009) The velocity of climate change. Nature, 462, 1052-1055.

765 Losos, J.B. (2011) Seeing the forest for the trees: The limitations of phylogenies in comparative biology: (American Society of Naturalists Address). The American Naturalist, 177, 709-727.

MacArthur, R.H. (1969) Patterns of communities in the tropics. Biological Journal of the Linnean Society, 1, 19-30.

770 Maddison, W.P. (2006) Confounding asymmetries in evolutionary diversification and character change. Evolution, 60, 1743-1746.

Magee, A.F., Höhna, S., Vasylyeva, T.I., Leaché, A.D. \& Minin, V.N. (2020) Locally adaptive Bayesian birth-death model successfully detects slow and rapid rate shifts. PLoS Computational Biology, 16, e1007999.

775 Mannion, P.D., Upchurch, P., Benson, R.B.J. \& Goswami, A. (2014) The latitudinal biodiversity gradient through deep time. Trends in Ecology and Evolution, 29, 42-50.

McPeek, M.A. \& Brown, J.M. (2000) Building a regional species pool: Diversification of the Enallagma damselflies in eastern North America. Ecology, 81, 904-920.

780 McPeek, M.A. \& Gavrilets, S. (2006) The evolution of female mating preferences: Differentiation from species with promiscuous males can promote speciation. Evolution, 60, 1967-1980.

Meseguer, A.L. \& Condamine, F.L. (2020) Ancient tropical extinctions at high latitudes contributed to the latitudinal diversity gradient. Evolution, 74, 1966-1987.

785 Milá, B., McCormack, J.E., Castañeda, G., Wayne, R.K. \& Smith, T.B. (2007) Recent postglacial range expansion drives the rapid diversification of a songbird lineage 
in the genus Junco. Proceedings of the Royal Society of London B: Biological Sciences, 274, 2653-2660.

Miller, E.C. \& Román-Palacios, C. (2021) Evolutionary time best explains the latitudinal diversity gradient of living freshwater fish diversity. Global Ecology and Biogeography, 30, 749-763.

Misof, B., Liu, S., Meusemann, K., Peters, R.S., Donath, A., Mayer, C., Frandsen, P.B., Ware, J., Flouri, T., Beutel, R.G. \& others (2014) Phylogenomics resolves the timing and pattern of insect evolution. Science, 346, 763-767.

Mittelbach, G.G., Schemske, D.W., Cornell, H.V., Allen, A.P., Brown, J.M., Bush, M.B., Harrison, S.P., Hurlbert, A.H., Knowlton, N., Lessios, H.A. \& others (2007) Evolution and the latitudinal diversity gradient: Speciation, extinction and biogeography. Ecology Letters, 10, 315-331.

Moen, D. \& Morlon, H. (2014) Why does diversification slow down? Trends in Ecology and Evolution, 29, 190-197.

Morales-Barbero, J., Martinez, P.A., Ferrer-Castán, D. \& Olalla-Tárraga, M.Á. (2018) Quaternary refugia are associated with higher speciation rates in mammalian faunas of the Western Palaearctic. Ecography, 41, 607-621.

Moritz, C., Patton, J.L., Schneider, C.J. \& Smith, T.B. (2000) Diversification of rainforest faunas: An integrated molecular approach. Annual Review of Ecology and Systematics, 31, 533-563.

Morley, R.J. (2007) Tropical rainforest responses to climatic change. Tropical rainforest responses to climatic change (ed. by M. Bush), J. Flenley), and W. Gosling), pp. 1-31. Springer, Berlin, Germany.

810 Morlon, H., Potts, M.D. \& Plotkin, J.B. (2010) Inferring the dynamics of diversification: A coalescent approach. PLoS Biology, 8, e1000493.

Owens, H.L., Lewis, D.S., Dupuis, J.R., Clamens, A.L., Sperling, F.A., Kawahara, A.Y., Guralnick, R.P. \& Condamine, F.L. (2017) Latitudinal diversity gradient in New World swallowtail butterflies is caused by contrasting patterns of outâ ofâ and intoâ theâ tropics dispersal. Global ecology and biogeography.

Paulson, D.R. (2001) Recent Odonata records from southern Florida-effects of global warming? International Journal of Odonatology, 4, 57-69.

Pianka, E.R. (1966) Latitudinal gradients in species diversity: A review of concepts. American Naturalist, 100, 33-46.

820 Pigot, A.L., Phillimore, A.B., Owens, I.P.F. \& Orme, C.D.L. (2010) The shape and temporal dynamics of phylogenetic trees arising from geographic speciation. Systematic Biology, 59, 660-673. 
Polato, N.R., Gill, B.A., Shah, A.A., Gray, M.M., Casner, K.L., Barthelet, A., Messer, P.W., Simmons, M.P., Guayasamin, J.M., Encalada, A.C. \& others (2018) Narrow thermal tolerance and low dispersal drive higher speciation in tropical mountains. Proceedings of the National Academy of Sciences, 115, 12471-12476.

Price, T.D. (2010) The roles of time and ecology in the continental radiation of the Old World leaf warblers (Phylloscopus and Seicercus). Philosophical Transactions of the Royal Society B: Biological Sciences, 365, 1749-1762.

830 Pyron, R.A. (2014) Temperate extinction in squamate reptiles and the roots of latitudinal diversity gradients. Global Ecology and Biogeography, 23, 1126-1134.

Pyron, R.A. \& Wiens, J.J. (2013) Large-scale phylogenetic analyses reveal the causes of high tropical amphibian diversity. Proceedings of the Royal Society B: Biological Sciences, 280, 20131622.

835 R Core Team (2021) R: A language and environment for statistical computing.

Rabosky, D.L. (2009) Ecological limits and diversification rate: Alternative paradigms to explain the variation in species richness among clades and regions. Ecology letters, 12, 735-743.

Rabosky, D.L., Chang, J., Title, P.O., Cowman, P.F., Sallan, L., Friedman, M., Kaschner, gradient in speciation rate for marine fishes. Nature, 559, 392-395.

Ree, R.H. \& Sanmartín, I. (2009) Prospects and challenges for parametric models in historical biogeographical inference. Journal of Biogeography, 36, 1211-1220.

Revell, L.J., Harmon, L.J. \& Glor, R.E. (2005) Under-parameterized model of sequence evolution leads to bias in the estimation of diversification rates from molecular phylogenies. Systematic Biology, 54, 973-983.

Rolland, J., Condamine, F.L., Beeravolu, C.R., Jiguet, F. \& Morlon, H. (2015) Dispersal is a major driver of the latitudinal diversity gradient of c arnivora. Global Ecology and Biogeography, 24, 1059-1071.

850 Rolland, J., Condamine, F.L., Jiguet, F. \& Morlon, H. (2014) Faster speciation and reduced extinction in the tropics contribute to the mammalian latitudinal diversity gradient. PLoS biology, 12, e1001775.

Ronquist, F., Klopfstein, S., Vilhelmsen, L., Schulmeister, S., Murray, D.L. \& Rasnitsyn, A.P. (2012) A total-evidence approach to dating with fossils, applied to the early radiation of the Hymenoptera. Systematic Biology, 61, 973-999.

Rosenzweig, M.L. \& others (1995) Species diversity in space and time.

Roy, K. \& Goldberg, E.E. (2007) Origination, extinction, and dispersal: Integrative models for understanding present-day diversity gradients. the american naturalist, 170, S71-S85. 
860 Rundell, R.J. \& Price, T.D. (2009) Adaptive radiation, nonadaptive radiation, ecological speciation and nonecological speciation. Trends in Ecology \& Evolution, 24, 394399.

Salisbury, C.L., Seddon, N., Cooney, C.R. \& Tobias, J.A. (2012) The latitudinal gradient in dispersal constraints: Ecological specialisation drives diversification in tropical birds. Ecology Letters, 15, 847-855.

Saupe, E.E., Myers, C.E., Peterson, A.T., Soberón, J., Singarayer, J., Valdes, P. \& Qiao, H. (2019) Spatio-temporal climate change contributes to latitudinal diversity gradients. Nature ecology \& evolution, 3, 1419-1429.

Sánchez-Ramírez, S., Tulloss, R.E., Guzmán-Dávalos, L., Cifuentes-Blanco, J., Valenzuela, R., Estrada-Torres, A., Ruán-Soto, F., Díaz-Moreno, R., HernándezRico, N., Torres-Gómez, M. \& others (2015) In and out of refugia: Historical patterns of diversity and demography in the North American Caesar's mushroom species complex. Molecular Ecology, 24, 5938-5956.

Schemske, D.W., Mittelbach, G.G., Cornell, H.V., Sobel, J.M. \& Roy, K. (2009) Is there 875 a latitudinal gradient in the importance of biotic interactions? Annu. Rev. Ecol. Evol. Syst., 40, 245-269.

Schluter, D. (2016) Speciation, ecological opportunity, and latitude: (American Society of Naturalists Address). The American Naturalist, 187, 1-18.

Schluter, D. \& Pennell, M.W. (2017) Speciation gradients and the distribution of biodiversity. Nature, 546, 48-55.

Schluter, D., Price, T., Mooers, A.Ø. \& Ludwig, D. (1997) Likelihood of ancestor states in adaptive radiation. Evolution, 51, 1699-1711.

Siepielski, A.M., Hasik, A.Z. \& Ousterhout, B.H. (2018) An ecological and evolutionary perspective on species coexistence under global change. Current opinion in insect science, 29, 71-77.

Siepielski, A.M., Hung, K.-L., Bein, E.E.B. \& McPeek, M.A. (2010) Experimental evidence for neutral community dynamics governing an insect assemblage. Ecology, 91, 847-857.

Smith, B.T., Bryson Jr, R.W., Houston, D.D. \& Klicka, J. (2012) An asymmetry in niche conservatism contributes to the latitudinal species diversity gradient in New World vertebrates. Ecology Letters, 15, 1318-1325.

Spano, C.A., Hernández, C.E. \& Rivadeneira, M.M. (2016) Evolutionary dispersal drives the latitudinal diversity gradient of stony corals. Ecography, 39, 836-843.

Stadler, T. (2011) Mammalian phylogeny reveals recent diversification rate shifts. Proceedings of the National Academy of Sciences, 108, 6187-6192. 
Stephens, P.R. \& Wiens, J.J. (2003) Explaining species richness from continents to communities: The time-for-speciation effect in emydid turtles. The American Naturalist, 161, 112-128.

Stevens, R.D. (2006) Historical processes enhance patterns of diversity along latitudinal gradients. Proceedings of the Royal Society B: Biological Sciences, 273, 22832289.

Suvorov, A., Scornavacca, C., Fujimoto, M.S., Bodily, P., Clement, M., Crandall, K.A., Whiting, M.F., Schrider, D.R. \& Bybee, S.M. (2021) Deep ancestral introgression shapes evolutionary history of dragonflies and damselflies. Systematic Biology, syab063.

Svensson, E.I. (2012) Non-ecological speciation, niche conservatism and thermal adaptation: How are they connected? Organisms Diversity \& Evolution, 12, 229_ 240.

Svensson, E.I., Eroukhmanoff, F. \& Friberg, M. (2006) Effects of natural and sexual selection on adaptive population divergence and premating isolation in a damselfly. Evolution, 60, 1242-1253.

Svensson, E.I., Gómez-Llano, M.A., Torres, A.R. \& Bensch, H.M. (2018) Frequency dependence and ecological drift shape coexistence of species with similar niches. The American Naturalist, 191, 691-703.

915 Tanentzap, A.J., Igea, J., Johnston, M.G. \& Larcombe, M.J. (2020) Does evolutionary history correlate with contemporary extinction risk by influencing range size dynamics? The American Naturalist, 195, 569-576.

Tiley, G.P., Poelstra, J.W., Dos Reis, M., Yang, Z. \& Yoder, A.D. (2020) Molecular clocks without rocks: New solutions for old problems. Trends in Genetics.

920 Toussaint, E.F.A., Bybee, S.M., Erickson, R.J. \& Condamine, F.L. (2019) Forest giants on different evolutionary branches: Ecomorphological convergence in helicopter damselflies. Evolution, 73, 1045-1054.

Troast, D., Suhling, F., Jinguji, H., Sahlén, G. \& Ware, J. (2016) A global population genetic study of Pantala flavescens. PloS one, 11, e0148949.

925 Wallace, A.R. (1876) The geographical distribution of animals.

Wallace, A.R. (1878) Tropical nature, and other essays.

Waller, J.T. \& Svensson, E.I. (2017) Body size evolution in an old insect order: No evidence for Cope's Rule in spite of fitness benefits of large size. Evolution, 71, 2178-2193.

930 Weir, J.T. \& Schluter, D. (2004) Ice sheets promote speciation in boreal birds. Proceedings of the Royal Society of London. Series B: Biological Sciences, 271, 1881-1887. 
Weir, J.T. \& Schluter, D. (2007) The latitudinal gradient in recent speciation and extinction rates of birds and mammals. Science, 315, 1574-1576.

935 Wickham, H. (2016) ggplot2: Elegant graphics for data analysis.

Wiens, J.J. (2007) Global patterns of diversification and species richness in amphibians. the american naturalist, 170, S86-S106.

Wiens, J.J. (2011) The causes of species richness patterns across space, time, and clades and the role of "ecological limits." The Quarterly Review of Biology, 86, 75-96.

940 Wiens, J.J. \& Donoghue, M.J. (2004) Historical biogeography, ecology and species richness. Trends in ecology \& evolution, 19, 639-644.

Wiens, J.J. \& Graham, C.H. (2005) Niche conservatism: Integrating evolution, ecology, and conservation biology. Annu. Rev. Ecol. Evol. Syst., 36, 519-539.

Wikelski, M., Moskowitz, D., Adelman, J.S., Cochran, J., Wilcove, D.S. \& May, M.L.

945 (2006) Simple rules guide dragonfly migration. Biology letters, 2, 325-329.

Wills, M.A. (2001) How good is the fossil record of arthropods? An assessment using the stratigraphic congruence of cladograms. Geological Journal, 36, 187-210.

Wilson, E.O. \& MacArthur, R.H. (1967) The theory of island biogeography.

Wright, S., Keeling, J. \& Gillman, L. (2006) The road from Santa Rosalia: A faster tempo of evolution in tropical climates. Proceedings of the National Academy of Sciences, 103, 7718-7722.

Yu, G., Smith, D., Zhu, H., Guan, Y. \& Lam, T.T.-Y. (2017) ggtree: An R package for visualization and annotation of phylogenetic trees with their covariates and other associated data. Methods in Ecology and Evolution, 1, 28-36.

955 Zheng, D., Wang, B. \& Chang, S.-C. (2017) Palaeodisparoneura cretacica sp. Nov., A new damselfly (Odonata: Zygoptera: Platycnemididae) from mid-Cretaceous Burmese amber. Comptes Rendus Palevol, 16, 235-240. 


\section{Figure legends}

960 Figure 1. Coenagrionoidea phylogeny showing five main clades of interest in previous systematic studies (Dijkstra et al., 2014). We specified sampling fractions for each of these clades in the episodic birth-death (EBD) models used to investigate the temporal dynamics of diversification in this superfamily (see Methods). The illustrated species and sampling fractions are as follows: 'core' pond damselflies (faimily Coenagrionidae, $\mathrm{N}=290 / 672$ ): Acanthagrion

965 temporale, dancers (faimily Coenagrionidae, genus Argia; $\mathrm{N}=91 / 132$ ): Argia apicalis, neotropical threadtails (faimily Coenagrionidae, previously classified as Proteneuridae, $\mathrm{N}=$ 44/107): Neoneura confundens, other 'ridge-face' pond damselflies [faimily Coenagrionidae; $\mathrm{N}=$ 131/449]: Telebasis demarara, featherlegs (family Platycnemididae; $\mathrm{N}=113 / 445$ ): Mesocnemis singularis. Photos: EIS and Erland Refling Nielsen (N. confundens).

970 Figure 2. Inferring the biogeographic history of pond damselflies and their relatives the featherlegs (superfamily Coenagrionoidea). Speciation times and ancestral ranges were jointly estimated using a time-heterogeneous continuous-time Markov model, based on empirical paleogeography, a secondary calibration and molecular and distribution data of 669 extant taxa. The empirical paleogeographic model in Landis (2017) was used to determine dispersal edges

975 between 25 geographic areas across the globe (Greenland, Antarctica (E) and Antarctica (W) not shown in the colour legend) and according to 3 different dispersal modes (see Methods and Appendix S1). Phylogenetic inference was summarized using a maximum a posteriori (MAP) tree. The distribution areas occupied by each of the extant taxa are shown at the tips of the tree. Pies show the proportion of each ancestral state in a random sample of 1000 posterior trees. The

980 cladogram in the lower right shows the inferred ancestral ranges for the most recent common ancestor of Coenagrionoidea, and for each of the three major clades in the superfamily. The fraction of taxa sampled is shown in parenthesis. One representative species is illustrated for each 
clade: Acanthagrion adustum ('core'), Leptagrion elongatum (ridge-face'), Platycnemis pennipes (featherlegs). Photos: EIS.

985 Figure 3. Posterior distribution of age estimates for the MRCA of pond damselflies and fetherlegs, under three alternative biogeogrphic dating models. The "strongly informed + paleo" model uses the empirical paleographic model in Landis (2017) to inform divergence times throughout the tree and a strong, normally distributed prior on the root age, with mean $=120$ and sd = 20 mya, based on two recent phylogenomic studies (Kohli et al., 2020; Suvorov et al., 2021).

990 The "weakly informed + paleo" model uses the same empirical paleographic model, but assumes a priori that Coenagrionoidea could have originated any time, with equal probability, between 240-40 mya. Finally, the "weakly informed, no paleo" model was used to confirm that biogeographic dating does not introduce unexpected biases in node ages. It does not incorporate any paleogeographic data and assumes that Coenagrionoidea could have originated any time, with 995 equal probability, between 240-0 mya.

Figure 4. Diversification rate changes since the MRCA of Coenagrionoidea: a) speciation, b) extinction and d) net diversification. Diversification rates were estimated on the maximum $a$ posteriori (MAP) tree from the biogeographic phylogenetic dating analysis using a root age calibration based of previous phylogenomic studies (Kohli et al., 2020; Suvorov et al., 2021).

1000 Changes in diversification rates were modeled under an episodic birth-death (EBD) process, over 20 equal-length time intervals and assuming autocorrelation among consecutive time intervals (see Appendix S1).

Figure 5. Latitudinal effects on diversification of pond damselflies and their relatives the featherlegs (superfamily Coenagrionoidea). (a) Speciation and (b) extinction rates at tropical and 1005 temperate latitudes were estimated using a Hidden-State Dependent Speciation and Extinction (HiSSE) model that accounts for background heterogeneity in diversification rates across the phylogeny, by including a hidden trait with two states. (c) Diversification was calculated as the 
net difference between speciation and extiction and (d) turnover was calculated as the ratio between extinction and speciation. The histograms show the posterior distribution of parameter

1010 estimates.

Figure 6. The contribution of trans-latitudinal dispersal to phylogenetic diversity in the tropics and in temperate areas. The histograms show the posterior distribution of outgoing and incoming dispersal rates for each latitudinal region. "Phylogentic dispersal rates" are calculated as the ratio of dispersal events to phylogenetic diversity apportioned by a latitudinal region and assuming

1015 dispersal occurs at the midpoints of tree edges (see Appendix S1). (a) Dispersal rates were calculated across a random sample of 1000 posterior trees from the joint inference of ancestral biogeographic areas and divergence times. (b) Dispersal events were sampled by stochastic character mapping during the HiSSE analyses and dispersal rates were calculated from this sample of events (see Appendix S1). 


\section{Core Ridge-face Argia \\ Threadtails Featherlegs}

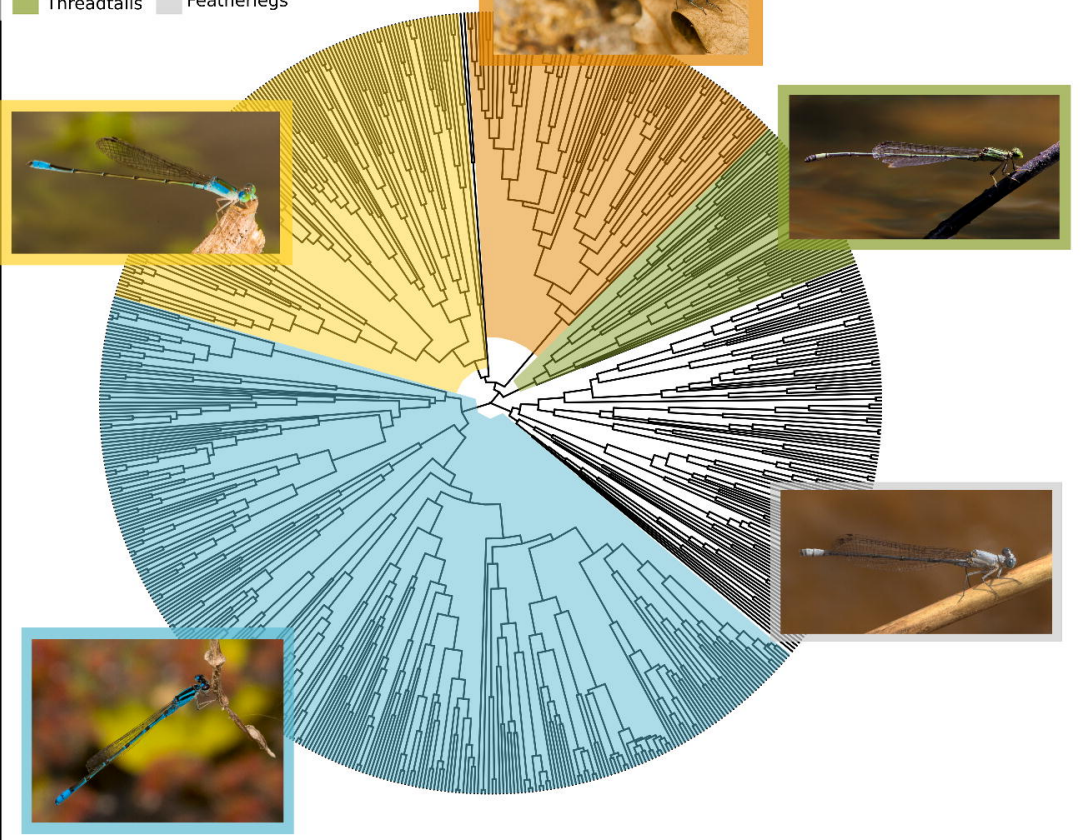




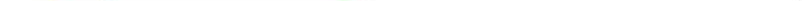




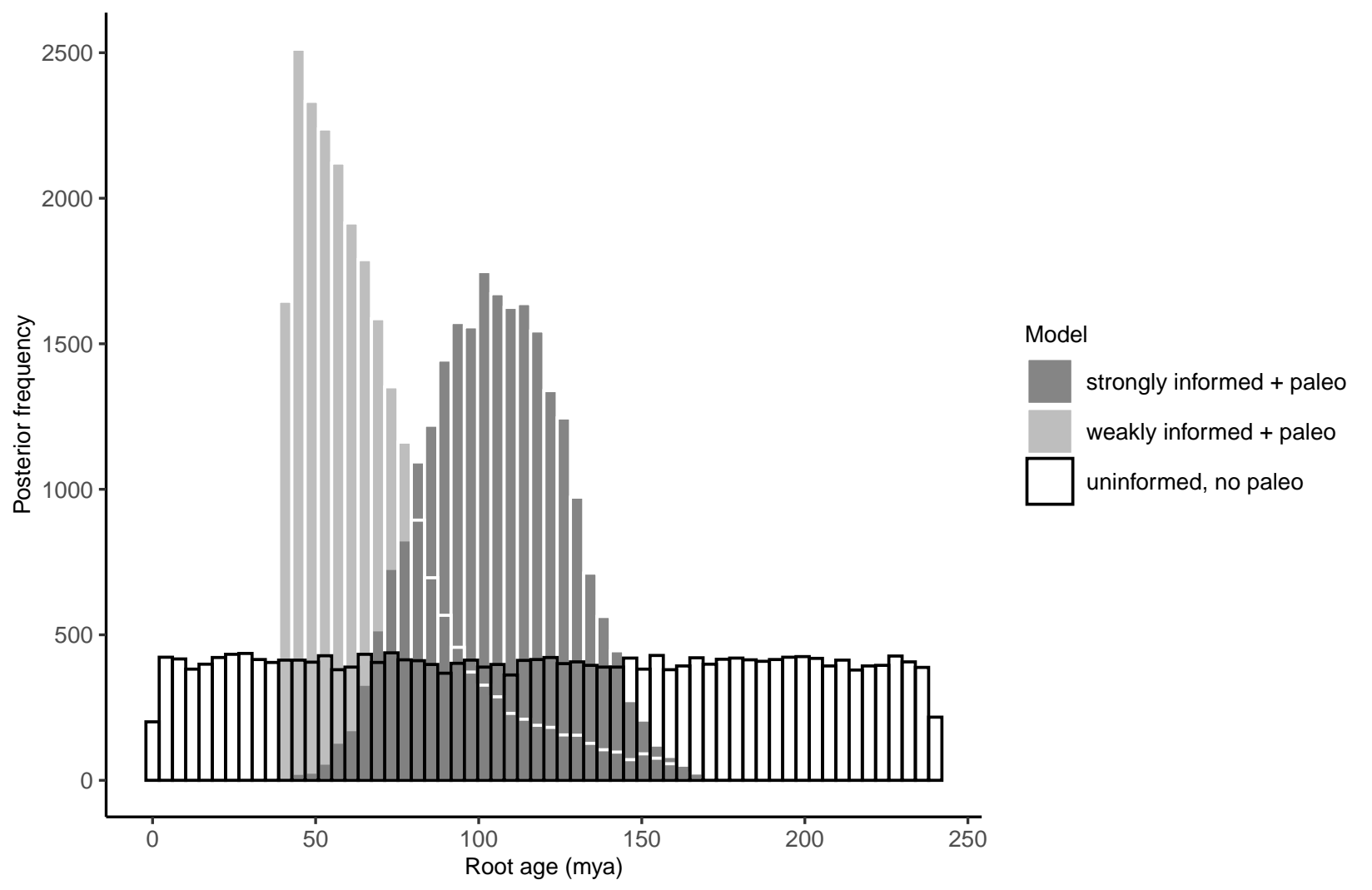


(a)

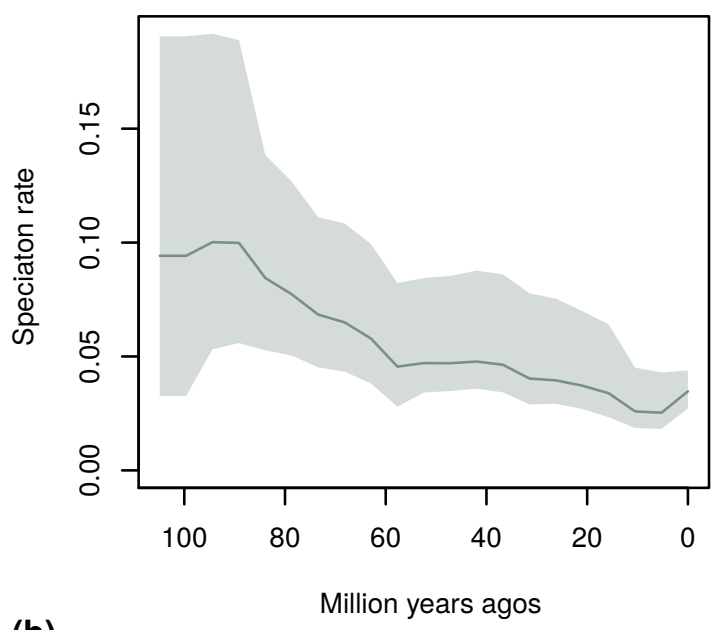

(b)

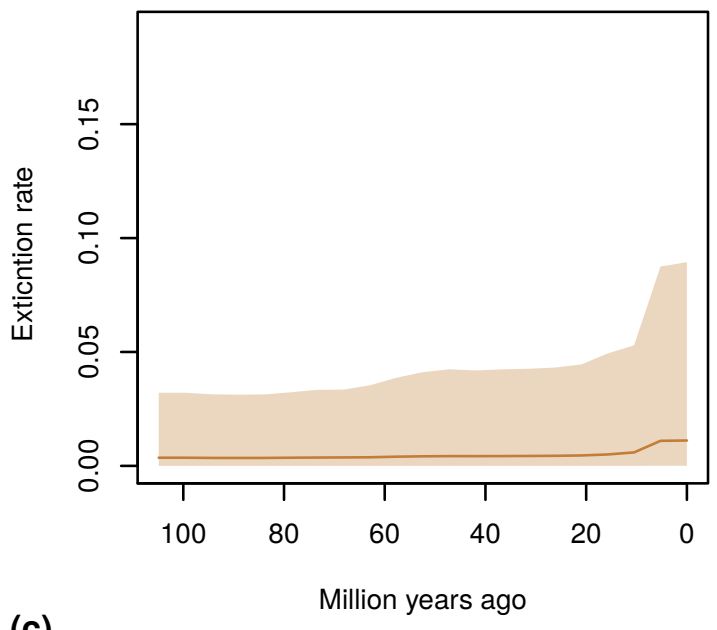

(c)

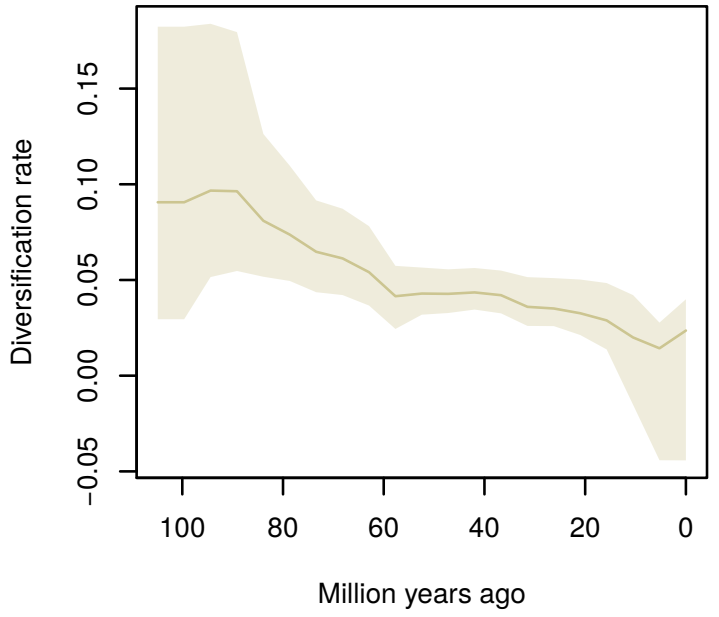


